\title{
A dominação- exploração das mulheres na sociedade capitalista: um estudo bibliográfico
}

Maria Júlia Tavares Pereira ${ }^{1}$

\section{RESUMO}

Este artigo propõe a revisão de uma bibliografia crítica quanto ao lugar ocupado pelas mulheres trabalhadoras na sociedade de classes. O desenvolvimento de análises críticas sobre sociedade capitalista e patriarcado ocorreu a partir das décadas de 1970 e 1980. Neste contexto, o trabalho era uma categoria central para a investigação da realidade social e do espaço ocupado pela mulher no modo de sociabilidade capitalista. Desde então, houve uma retração em tais debates e nas tentativas de compreender a síntese entre trabalho produtivo e reprodutivo. Assim, este artigo procura dar ênfase ao conceito de divisão sexual do trabalho e sua influência na produção dos gêneros, bem como na perpetuação da marginalização da mulher na sociedade de classes. De caráter qualitativo e exploratório, a metodologia combina revisão bibliográfica sobre a temática, com o levantamento de dados estatísticos que possam elucidar a relevância da discussão. Conclui-se, segundo a literatura evidenciada, que o processo de proletarização do trabalho feminino não alterou sua dimensão reprodutiva, mas aumentou sua intensidade, constituindo um processo de dominação-exploração das mulheres na sociedade capitalista.

Palavras-chave: Gênero; Trabalho feminino; Capitalismo.

\section{ABSTRACT}

This article proposes a review of a critical bibliography on the place occupied by working women in class society. The development of critical

${ }^{1}$ Graduanda do curso de Ciências Sociais, da Universidade Federal de Alfenas-Unifal; Membro do grupo de pesquisa Filosofia, História e Teoria Social; majutavares97@gmail.com. 
theories that analyze the capitalist society and its relationship with patriarchy started on the 1970s and 1980s. Then, work was a central category for the investigation of social reality and the space occupied by women in the capitalist sociability. Since then, there has been a retraction in such debates and the attempt to consider the synthesis between productive and reproductive work. Thus, this article seeks to emphasize the concept of sexual division of labor and its influence in the production of the genres, as well as in the perpetuation of the marginalization of the woman today. The methodology it's composed by bibliographical revision and statistical data, in order to clarify the relevance of the discussion. It concludes, according to the literature, that the proletarianization of female labor didn't change its reproductive dimension, but increased its intensity, constituting a dominationexploration process of women in capitalist society.

Keywords: Gender; Female work; Capitalism.

\begin{abstract}
A situação da mulher na sociedade é tema amplamente debatido em ambientes acadêmicos, na mídia e em espaços políticos. Tal temática ocupa posição de destaque também nas Ciências Sociais e foi estudada a partir de perspectivas diversas, que elucidam a relevância das problemáticas femininas e relações de gênero.

Com o intuito de evidenciar o movimento de mercantilização no feminino, e suas consequências, estudos de gênero passaram a ser desenvolvidos no Brasil, especialmente entre os anos 1980 e 1990. Emergiram análises que evidenciavam as relações entre responsabilidades domésticas e feminilidade e constatou-se que era preciso pensar a situação da mulher na sociedade de classes não somente por um viés econômico, como também a partir do questionamento da dimensão da afetividade.

Por conta da permanência do impacto das responsabilidades domésticas sobre a vida das mulheres trabalhadoras, compreendemos ser necessário o movimento de agregar as análises das esferas produtivas às das esferas reprodutivas. É mister, portanto, a tentativa de
\end{abstract}


compreender o processo de sexualização do trabalho, porque "já não é o estágio das forças produtivas que determina a subordinação das mulheres no trabalho, mas as próprias relações de trabalho que são sexualizadas e vistas como portadoras da hierarquia de gênero" (SOUZALOBO, 2011, p. 166).

A caracterização do trabalho feminino é aqui considerada a principal forma de compreensão da posição ocupada pelas mulheres na sociedade, portanto este artigo pretende retomar questões recorrentes em estudos sobre problemáticas femininas (SAFFIOTI, 1976), que revelam os mecanismos de sexualização do trabalho. Por reconhecermos a importância do labor feminino, procuramos evidenciar perspectivas teórico-conceituais sobre força de trabalho e relações sociais de sexo.

O artigo está dividido em seções, que dialogam com as principais perspectivas sobre o tema do trabalho feminino e relações sociais de sexo - como as contribuições de Cristina Bruschini (1993), Jules Falquet (2008), Helena Hirata (2002), Elisabeth Souza-Lobo (2011), Flávia Biroli (2018) e Heleieth Saffioti (2004). A primeira seção trata do campo de estudos no qual a temática está inserida, dialogando com a segunda seção, na medida em que esta trata de um conceito amplamente utilizado pelos(as) autores(as). A terceira seção dá ênfase a discussão teórica realizada com foco na realidade brasileira, valendo-se do uso de dados estatísticos.

Optou-se pela revisão bibliográfica enquanto metodologia, pois, valendo-se dela, é possível pensar sobre o problema e apurar a questão de pesquisa (STAKE, 2011). Isso porque, toda "pesquisa que se queira científica necessita apreender os conceitos e as categorias atinentes ao objeto investigado" (JANTSCH, p. 46, 2008). Enquanto forma de pensar, o esclarecimento do movimento dos conceitos pode possibilitar pesquisas futuras, bem como uma maior compreensão do campo de estudos no qual a temática em questão está inserida. 


\section{O campo de estudos}

A temática do trabalho feminino inseriu os estudos sobre a mulher na academia brasileira. Mesmo que nem todos(as) os(as) autores(as) que estudavam a questão se considerassem feministas, foi o feminismo que garantiu legitimidade ao tema enquanto enigma científico (BRUSCHINI, 1993). Isso porque, o trabalho como objeto da Sociologia há muito tempo era considerado relevante e o feminismo viu, em sua análise, um potencial de transformação da realidade.

Em países considerados subdesenvolvidos, como o Brasil, o papel libertador do trabalho remunerado foi questionado e a ausência de estudos sobre o trabalho reprodutivo da mulher foi evidenciada. Autoras(es) - especialmente os que são aqui abordados - chamaram atenção para o caráter sexuado da força de trabalho, que passou a ser definida não somente enquanto oposição ao capital. Constatou-se que o sexo do trabalhador causa impactos na relação entre trabalho e capital, e a existência de uma parcela diferenciada da força de trabalho, composta pelas mulheres. Elas estariam duplamente sujeitas: aos homens e ao capital - por isso o uso do termo “dominação-exploração" feminina na sociedade capitalista justifica a abordagem do presente texto.

Os estudos sobre o trabalho feminino deram ênfase à articulação entre espaço produtivo e reprodutivo, já que para as trabalhadoras, ambas as esferas se relacionam. Segundo Bruschini (1993, p. 19):

\footnotetext{
Os ângulos pelos quais a atividade das mulheres foi percebida acompanham tendências sobre a análise do trabalho feminino, tal como se expressam nos estudos sobre mulher, em geral dedicando-se inicialmente a análise macrossociais da participação feminina no mercado de trabalho, para só mais tarde incorporar a necessária articulação entre trabalho e família.
} 
A divisão sexual do trabalho, que corresponde à "preexistência de relações sociais entre os sexos, vigentes em todos os espaços sociais, entre eles a fábrica e a família" (BRUSCHINI, 1993, p. 21), foi amplamente evidenciada. Posteriormente, o trabalho doméstico foi incorporado, com o intuito de alargar o conceito de trabalho, a fim de incluir o montante de atividades indispensáveis à produção social, cotidianamente realizadas por mulheres.

A temática emergiu com a intenção de desvendar a dinâmica da sexualização de relações sociais - assim como as relações étnicas e de geração, para que pudessem ser superadas idealizações conceituais. $\mathrm{Na}$ Sociologia do Trabalho,

[...] a partir dos anos 8o, quando pesquisadoras que já estudavam o trabalho feminino passam a problematizar a divisão sexual do trabalho na fábrica, que o uso da categoria gênero começa a ser pensado por este campo da Sociologia, que passa a incorporar questões como as diversas dinâmicas na configuração de postos masculinos e femininos e a não permutabilidade entre ambos (BRUSCHINI, 1993, p. 22).

Desse modo, o tema do trabalho feminino na academia foi ao encontro de uma análise das relações sociais entre os sexos. Entretanto, os estudos sobre a temática precisaram superar implicações teóricas que surgiram com a introdução de termos e conceitos, como o gênero.

Segundo Joan Scott (1995), a palavra "gênero" passou a ser utilizada pelas feministas com o intuito de evidenciar a organização social que perpassa as relações entre os sexos. Assim como na gramática, ele foi compreendido como um termo referente a um "sistema socialmente consensual de distinções” (p. 72). Nas Ciências Sociais, os(as) acadêmicos(as) se apropriaram dele para se aproximar de um discurso científico, distante da política associada ao feminismo.

Destacou-se a relevância das compreensões generalizadas sobre o que seriam as relações entre homens e mulheres, na construção de 
estruturas hierárquicas atuantes nas sociedades. Portanto, a categoria gênero remete a uma forma de dar significado às relações de poder. Neste contexto, Scott chama atenção para o fato de que os sistemas econômicos e os de gênero "operam simultaneamente para reproduzir as estruturas socioeconômicas e as estruturas de dominação masculina de uma ordem social particular" (1995, p. 79).

Saffioti (2004) dialoga com Scott, e compreende o gênero como "uma gramática social, regulando não apenas relações homem-mulher, mas também relações homem-homem e relações mulher-mulher" (p. 45).

A definição mais básica de gênero seria aquela que remete a construção social do masculino e do feminino - utilizada por Scott (1995), Saffioti (2004) e outros(as), para introduzir discussões mais complexas sobre o tema. Para além do que foi anteriormente apontado quanto ao uso do termo, ele foi empregado, especialmente, com o intuito de recusar um essencialismo biológico, que coloca a anatomia como destino. Saffioti, entretanto, destaca,

[...] o gênero não é tão somente social, dele participando também o corpo, quer como mão-de-obra, quer como objeto sexual, quer, ainda, como reprodutor de seres humanos, cujo destino, se fossem homens, seria participar ativamente da produção, e, quando mulheres, entrar com três funções na engrenagem descrita (2004, p. 125).

Portanto, para além do plano das significações e subjetividades, as definições do masculino e do feminino estão ligadas à realidade material, produtiva e reprodutiva, dos indivíduos.

Souza-Lobo identifica duas esferas sociais, distintas e interrelacionadas: "a produção social de bens, constituída basicamente por relações mercantis, e a reprodução dos seres humanos, estruturada por relações aparentemente naturais" (2011, p. 152). O gênero está 
diretamente relacionado a assimetria entre produção e reprodução, visto que a divisão sexual do trabalho engendrada por tal, estrutura as relações entre sexos nos espaços sociais. Segundo a autora,

\begin{abstract}
de fato, a problemática da divisão sexual do trabalho se articula com a categoria gênero e abre espaço para se pensar as novas questões que preocupam a sociologia do trabalho: as 'metamorfoses' do trabalho e o seu questionamento, a subjetividade no trabalho, e as identidades no trabalho, o problema de igualdade e diferenças $e$ as formas contemporâneas da gestão e de políticas sociais (SOUZALOBO, 2011, p. 202).
\end{abstract}

Desse modo, enquanto locus das relações de gênero, a divisão sexual do trabalho assume uma centralidade como categoria fundamental na análise das relações entre homens e mulheres. Ademais, o termo "gênero", enquanto desafio à Sociologia do Trabalho, nos impele a redefinições das próprias relações, ou interações, do trabalho.

\title{
Divisão sexual do trabalho
}

Com o objetivo de dar a devida atenção a relação entre trabalhos produtivo e reprodutivo, Helena Hirata e Danièle Kergoat (2007) utilizaram o termo divisão sexual do trabalho enquanto categoria de análise. De acordo com as autoras, na França, o termo é considerado categoria sociográfica, pois denomina ocupações diferenciadas de homens e mulheres, no mercado de trabalho e na distribuição do trabalho doméstico no lar.

A existência da divisão sexual do trabalho evidencia que as desigualdades entre homens e mulheres são sistemáticas e desvenda os mecanismos utilizados pela sociedade para realocar atividades femininas e masculinas de forma hierarquizada, criando um sistema de gênero. Para as autoras, é necessário admitir que o trabalho realizado 
gratuitamente pelas mulheres é invisível e não realizado somente para elas, mas sim para outros, justificando-se a partir daquilo que é naturalizado: amor e dever materno.

A divisão sexual do trabalho seria "um fator prioritário para a sobrevivência da relação social entre os sexos" (HIRATA; KERGOAT, 2007, p. 599), visto que é mediada por uma ideologia naturalista e equivale as práticas sociais e papéis sociais sexuados. Ela é regulamentada pelos princípios de separação e hierarquia; o trabalho produtivo é compreendido enquanto responsabilidade masculina, assim como as funções sociais, políticas, religiosas e militares, enquanto o trabalho reprodutivo é prioritário para as mulheres.

Visto que as normas sociais estão em constante movimento, novas configurações passaram a ser identificadas nas relações entre homens, mulheres e trabalho. Em sociedades do Norte, por exemplo, mulheres desempenham cada vez mais funções produtivas. Elas investem em suas carreiras mediante a externalização do trabalho reprodutivo, o que engendra um grande contingente de mulheres em situação precária que exercem trabalho doméstico remunerado, especialmente imigrantes. Se estabelece, então, "uma relação de classe entre as mulheres do Norte, empregadoras, e essa nova classe servil" (HIRATA; KERGOAT, 2007, p. 602).

A partir da externalização do trabalho doméstico, as relações de gênero se estabelecem de forma diversa: os conflitos nos casais são amenizados, enquanto há uma maior flexibilidade das mulheres quanto à demanda de seus trabalhos produtivos, permitindo uma conciliação entre vida reprodutiva e produtiva. Tal movimento perpetua a ideia de que há uma complementaridade entre os sexos, cuja gênese reside na tradição funcionalista da complementaridade de papéis.

A emergência do trabalho doméstico remunerado no Brasil está relacionada a imbricações de relações sociais de sexo, raça e classe. 
Ademais, o tempo desta atividade cotidiana passou a ser invadido pela lógica do trabalho produtivo. Em outras palavras, convém destacar que,

A análise sobre a variação da duração do tempo da execução das tarefas do trabalho doméstico é relevante para a apreensão da lógica temporal dessa atividade, que é formada tanto por uma sequência de tarefas variadas, com ou sem interrupções, como pela realização simultânea de tarefas e ainda por tarefas cujo desenrolar segue um ritmo próprio e singular a cada momento que se realiza, como as tarefas de cuidado (ÁVILA, 2016, p. 141).

Nesse contexto, é central a percepção do tempo de trabalho apropriado e destinado às tarefas domésticas, pois esse se relaciona a divisão sexual do trabalho e sua reprodução.

Segundo Ávila, no cotidiano, o trabalho doméstico remunerado e não remunerado é sustentado pelas relações entre as mulheres e a divisão sexual do trabalho entre gerações. As consequências do trabalho realizado pelas mulheres no cotidiano e a carência de tempo, fruto de tais responsabilidades específicas, não se apresenta somente na dimensão da pobreza, como também no envolvimento político, ou falta dele.

Biroli (2018) afirma que, falar da divisão sexual do trabalho demanda apontar o que foi e ainda é definido como trabalho de mulher, competência de mulher e lugar de mulher. Ademais, segundo ela, o uso do termo nos remete também às "dificuldades cotidianas que vão conformando trajetórias, possibilidades diferenciadas na vida de mulheres e homens" (p. 21).

De acordo com a autora, a família é um nexo importante na produção do gênero e da situação de vulnerabilidade das mulheres. Ela opta, para tratar da questão, pela noção de vulnerabilidade, visto que esta corresponderia mais acertadamente à situação das mulheres hoje. Desse modo, o gênero é, 
[...] produzido na forma da exploração do trabalho das mulheres e da vulnerabilidade relativa que incide sobre elas. Para ser mais precisa, diferenças codificadas como 'naturalmente' femininas ou masculinas, imprimindo às vivências uma concepção dual e binária de gênero, decorrem da atribuição distinta de habilidades, tarefas e alternativas na construção da vida de mulheres e homens (BIROLI, 2018, p. 35).

A partir dessa perspectiva, Biroli retoma a discussão inicial das autoras que optaram por utilizar o termo "gênero", especialmente nas Ciências Sociais. Migrou-se para a percepção dos comportamentos masculinos e femininos que desse conta das características sociais dos mesmos, afastando-se de narrativas que naturalizavam as práticas de homens e mulheres.

Para Biroli, estabelecer como se dão as relações entre trabalho não remunerado, trabalho remunerado e os arranjos familiares, é essencial para a compreensão da situação de dominação-exploração das mulheres na sociedade. Para tal, a divisão sexual do trabalho é variável importante, visto que nos permite estabelecer como se organizam as hierarquias de gênero.

Para o trabalho feminino, a dinâmica "de responsabilização desigual e restrições no acesso ao tempo, sobretudo quando as mulheres têm filhos pequenos, orienta sua presença no mercado de trabalho e seu acesso à renda" (BIROLI, 2018, p. 48). Por isso, a partir da análise do trabalho realizado no âmbito familiar, privado, é possível desvendar as hierarquias que organizam as relações dentro e fora dela.

\section{Trabalho feminino e a realidade brasileira}

Esta seção pretende expor como diferentes autoras mobilizaram conceitos e teorias sobre o trabalho feminino na análise de dados 
estatísticos e em propostas de intervenção sobre a realidade brasileira em diferentes momentos. Ademais, traz dados secundários considerados representativos da relevância da retomada das discussões deste artigo.

Quanto aos impactos da divisão sexual do trabalho sobre a relação das mulheres com o trabalho produtivo, Souza-Lobo (2011) examinou dados da População Economicamente Ativa (PEA) no Brasil, entre 1970 e 1975. A autora constatou que houve aumento da participação feminina no mercado de trabalho, especialmente nos setores de serviços e social - setores socialmente desvalorizados em termos salariais.

Souza-Lobo destaca que, em funções não atreladas à maternidade e ao trabalho doméstico, as trabalhadoras eram consideradas ilegítimas. Foi constatado que as mulheres estudavam mais, porém não alcançavam os postos mais altos na indústria, e que crescia o número de mulheres chefiando famílias e criando seus filhos sozinhas. Por isso, a autora sugere a necessidade de uma legislação que proteja os direitos das mulheres e reforce os deveres masculinos quanto aos cuidados com os filhos e/ou afazeres domésticos.

Para a autora, há normas sociais que retiram a possibilidade de que os homens vivenciem a paternidade, enquanto as mulheres vivem a maternidade de maneira intensa, tendo de renunciar, completa ou parcialmente, ao trabalho remunerado. Assim, compreender a maternidade e a paternidade enquanto vivências de homens e mulheres, parte de uma humanidade sexuada, e que implique em vivências sexuadas, é de extrema importância. Ademais, Souza-Lobo atesta a urgência da criação de creches e equipamentos coletivos que auxiliem nos cuidados e socialização das crianças, para que as trajetórias profissionais de homens e mulheres não sejam sacrificadas, ou haja dupla jornada. 
Abramo e Valenzuela (2016) também destacam a necessidade de que as estruturas políticas e de conciliação sejam intensificadas, para que se alcance a equidade de gênero, e limitações engendradas pelas responsabilidades de cuidado não causem grandes impactos na inserção das mulheres na vida laboral. Isso porque, a divisão entre trabalhos produtivo e reprodutivo promove hierarquização na sociedade e no mercado de trabalho, perpetuando as desigualdades de gênero. Pois,

Um fator-chave para facilitar a incorporação das mulheres ao mercado de trabalho e aliviar a tensão vivenciada tanto por elas como pelos homens com responsabilidades familiares e dupla jornada é a disponibilidade de serviços acessíveis de assistência a crianças, sobretudo em idade pré-escolar (ABRAMO, VELENZUELA, 2016, p. 115-116).

Mesmo em lares onde homens dedicam tempo às tarefas domésticas, a dedicação das mulheres aos cuidados familiares e a socialização de crianças, é mais elevada. Entretanto, outras perspectivas e artigos apresentam contrapontos a tais constatações. Pesquisa realizada valendo-se de 243 observações dos estados brasileiros, entre 2003 e 2011, constatou que, diferente do esperado, a disponibilidade de creches e escolas para crianças entre zero e cinco anos não engendrou redução dos diferenciais de gênero (LAVINAS et al., 2016).

Quanto ao uso do tempo, relatório elaborado pelo IPEA (2017) destaca que houve uma redução na quantidade de horas semanais dedicadas aos afazeres domésticos pelas mulheres. No entanto, o tempo médio dispendido pelos homens nas mesmas tarefas, manteve-se estável. O Gráfico 1 elucida tais alterações. 


\section{Gráfico 1}

Média de horas semanais dedicadas a afazeres domésticos da população de 16 anos ou mais de idade, por sexo e cor/raça - Brasil, 2001 a 2015

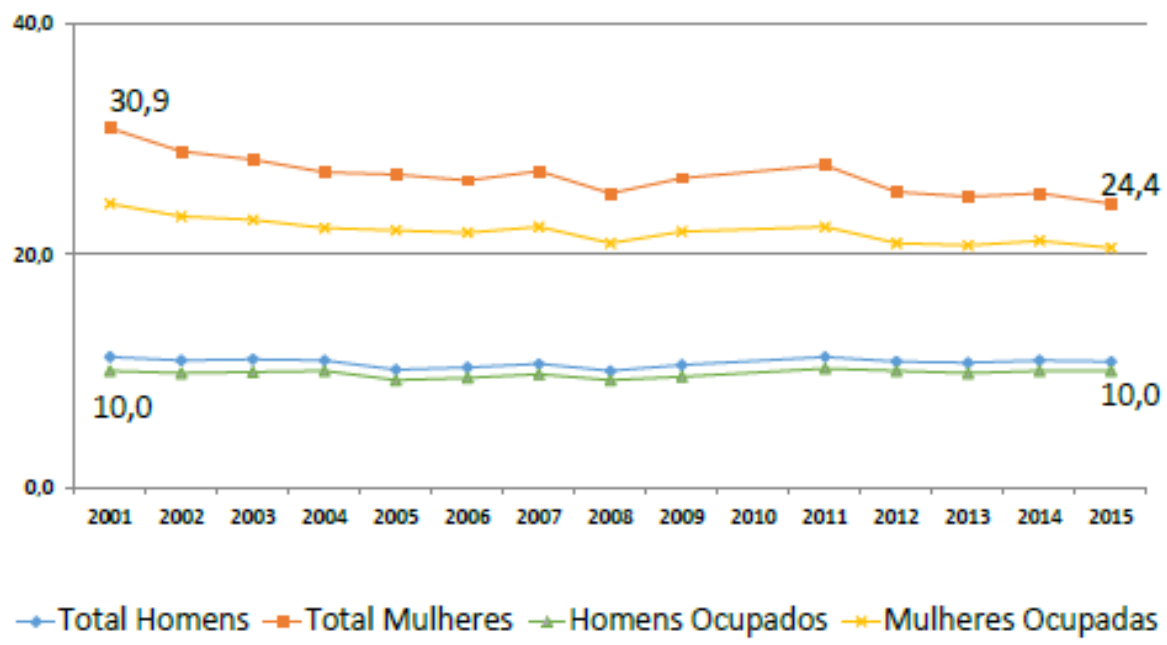
Fonte: Pnad/ IBGE Elaboração: IPEA/DISOC/NINSOC

Bruschini e Lombardi (200o) evidenciam que os afazeres domésticos ainda são considerados responsabilidades femininas, independentemente da situação social, da posição ocupada na família e/ou se desempenham trabalho produtivo fora do lar. Quando realizados no lar, pela dona-de-casa, tais afazeres são considerados inatividade econômica. No entanto, quando são contratadas pessoas para realizar as tarefas domésticas, o trabalho passa a ser considerado como serviço ou emprego doméstico. Ou seja, "as mesmas atividades têm significado diferente para a economia, caso sejam realizadas como prestação de serviços remunerados, ou por alguém da família, em geral uma mulher, sem qualquer pagamento" (BRUSCHINI; LOMBARDI, 200o, p. 70).

As autoras afirmam que há uma diferenciação entre o trabalho das empregadas domésticas e aqueles realizados por outros trabalhadores, visto que aquele não estabelece uma relação capitaltrabalho usualmente observada: as jornadas dos afazeres domésticos, para empregadas - e donas-de-casa -, não estão sujeitas a determinação de tempo ou ritmo. O elo entre as mulheres está presente no fato de que, 
é no trabalho de empregadas domésticas, que as profissionais usualmente se apoiarão para se dedicar à própria carreira. Ademais, o emprego doméstico elucida a constância de um nicho ocupacional de relevância para a força de trabalho feminina.

No entanto, é necessário destacar que há uma nítida tendência de raça/etnia no trabalho doméstico remunerado. O Gráfico 2 esclarece que, mesmo sendo maioria neste setor ocupacional (IPEA, 2017), a média de mulheres negras com carteira assinada é inferior à média das mulheres brancas. Outrossim, a diferença aumenta quando comparamos também as regiões do país. Em 2015, no Centro-Oeste, 37,5\% das trabalhadoras domésticas possuíam carteira assinada, enquanto na região Nordeste a proporção era de 19,5\% das trabalhadoras. Ademais, apesar do crescimento da formalização do setor e o maior número de trabalhadoras com carteira assinada, a renda média em 2015 era de R\$ 739 e não alcançava o valor do salário mínimo da época, $\mathrm{R} \$ 788$.

\section{Gráfico 2}

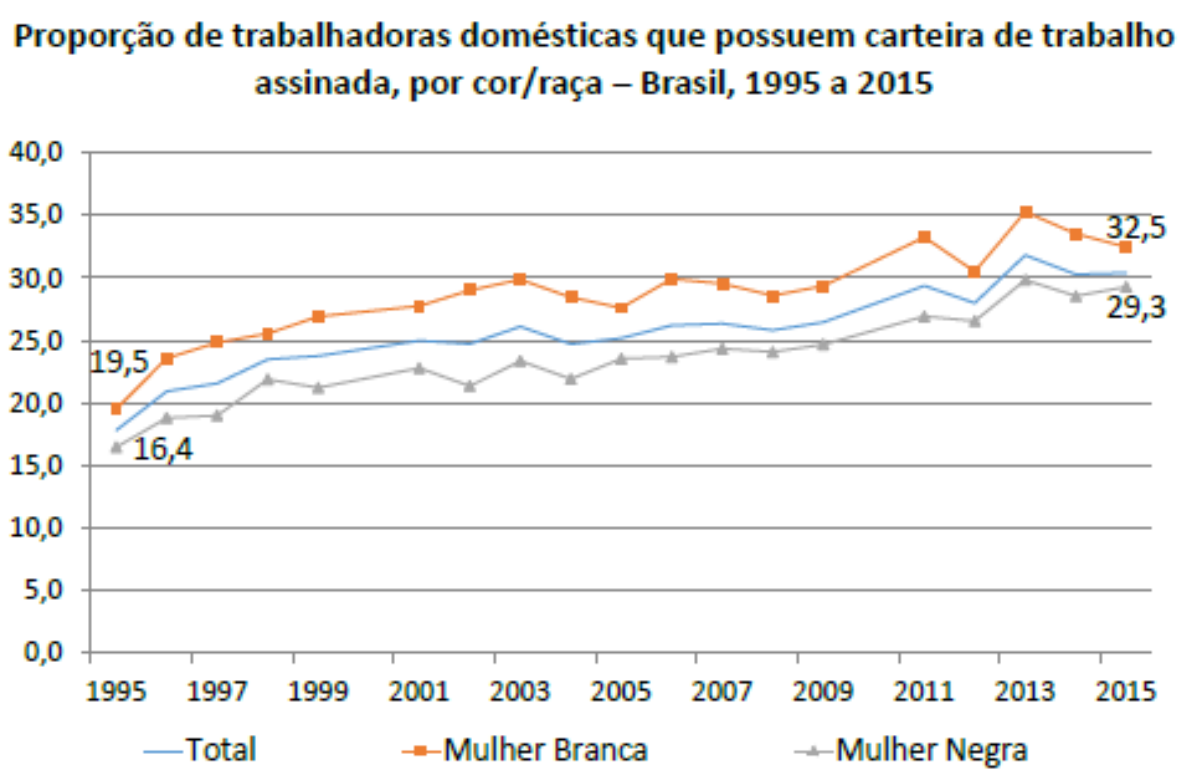

Fonte: Pnad/ IBGE Elaboração: IPEA/DISOC/NINSOC 
Quanto a visibilidade do trabalho das mulheres no Brasil, Guimarães e Brito (2016) destacam o modo pelo qual a atividade feminina é contabilizada em censos, pois ele reflete as formas de classificação do trabalho numa sociedade constantemente suscetível a mudanças. Segundo as autoras, a intensificação da participação feminina no mercado de trabalho está inserida num movimento amplo de mercantilização do trabalho no Brasil. As taxas de atividade refletem um processo histórico, caracterizado por mudanças nas ocupações das mulheres no mercado, assim como mudanças na apreensão a contabilização realizadas pelos censos. As categorias censitárias utilizadas "foram sendo atualizadas, reinventadas em sua métrica, para dar conta da nova realidade que se apresentava aos gestores" (GUIMARÃES; BRITO, 2016, p. 77).

A forma pela qual categorias censitárias se estabelecem, pode contribuir para visibilizar ou manter invisível o trabalho feminino. Assim, "o modo de representar a presença feminina na atividade econômica é também uma construção social” (GUIMARÃES; BRITO, 2016, p. 78). É importante considerar que as constatações sobre a intensificação da presença feminina nos dados sobre o mercado de trabalho, podem ser consequência de uma nova forma de classificar e contar a atividade feminina. $O$ aumento indicaria a superação da subestimação do trabalho feminino que, anteriormente, escapava da definição cultural e institucional de atividade econômica.

Os censos de 1940 e 1950, por exemplo, caracterizavam os indivíduos de acordo com o local no qual exerciam a atividade, não de acordo com seu caráter econômico ou não econômico. Assim, o trabalho realizado nos domicílios não era contabilizado. A contribuição das autoras está na ênfase dada por elas aos efeitos das perguntas feitas nos censos, que podem produzir efeitos na forma como o resultado é contabilizado. 
Os censos evitaram, por muito tempo, o contexto doméstico do trabalho, relevante principalmente para as mulheres. Não obstante, eles ainda possibilitaram discussões teórico-conceituais, como, por exemplo, aquela que contestou a hipótese de que a expansão do capitalismo excluiria as mulheres do mercado de trabalho (SOUZA-LOBO, 2011).

Diferente do que foi amplamente difundido, a força de trabalho feminina sempre constituiu algo além de um acessório, um complemento para o rendimento familiar. Entretanto, em diferentes países, foi lento o processo que passou a considerar, tornar visível e quantificável o assalariamento das atividades desempenhadas por mulheres. A relevância da forma pela qual se contabiliza o trabalho feminino está no fato de que há diferenças entre ele, atividade e emprego (MARUANI; MERON, 2016). Exemplo disso é a dificuldade em se determinar a diferença, em dados estatísticos, entre uma mulher desempregada e uma dona-de-casa.

\section{Conclusão}

Como proposto, o artigo examinou uma literatura teórico-crítica sobre trabalho feminino e sua relação com a divisão sexual do trabalho. Observou-se que a condição que se apresenta não é favorável para a anulação de determinantes que colocam as mulheres em posição de desvantagem no mercado de trabalho mais qualificado, ou seja, pela necessidade de conciliar trabalhos remunerado e doméstico, as mulheres ocupam grande parte dos empregos informais.

Ademais, a intensificação da participação feminina no mercado de trabalho não promoveu uma superação da vulnerabilidade a que as mulheres estão sujeitas na sociedade. A sociabilidade capitalista impõe limites a práxis dos indivíduos e as formas de experienciar a vida, como também a articulação de relações com outros indivíduos e aos lugares 
ocupados por eles no mundo. Tais limites não são os mesmos para todos, visto que o sexo, a raça/etnia, a classe social, bem como a região do país/globo onde o indivíduo vive e a idade, causam impactos os mais diversos para categorias sociais específicas. As mulheres, as adolescentes e as sexagenárias, por exemplo, são a maioria da população mais empobrecia do planeta (FALQUET, 2008).

Quanto a posição das mulheres na sociedade de classes, é mister apontar que, ainda que haja pouco emprego, ou que seu trabalho não seja visível, a atividade feminina é onipresente na sociedade Ocidental. Por isso, é necessário pensar o fim do trabalho em sua organização dominante como emprego assalariado, para que outras configurações do trabalho sejam incluídas e o conceito seja expandido (HIRATA, 2002).

Para concluir, reiteramos a relevância de estudos que visam desvendar os mecanismos que atuam na perpetuação da duplicidade do trabalho feminino, constituído pela produção e reprodução da existência numa situação social em que se ampliaram as condições estruturais de precarização e degradação do trabalho às quais as mulheres estão cada vez mais submetidas. O processo de proletarização de uma parcela da força de trabalho não foi concomitante a maior equidade no espaço doméstico, e o caráter reprodutivo do trabalho feminino permanece constitutivo das relações sociais entre os sexos. Retomar estudos que colocam em evidência tal situação, nos permite avançar na compreensão da complexidade da realidade social e suas contradições, bem como lutar pela construção de uma sociedade mais justa e igualitária.

\section{REFERÊNCIAS}

ABRAMO, Lais; VALENZUELA, Maria Elena. Tempo de trabalho remunerado e não remunerado na América Latina-Uma repartição desigual. In.: ABREU, Alice Rangeu de Paiva; HIRATA, Helena; LOMBARDI, Maria Rosa (Orgs). Gênero e trabalho no Brasil e na 
França: perspectivas interseccionais. São Paulo: Editora Boitempo, 2016.

ANTSCH, Ari Paulo. Os conceitos no ato teórico-metodológico do labor científico. In.: BIANCHETTI, Lucídio; MEKSENAS, Paulo (Orgs.). A trama do conhecimento: Teoria, método e escrita em ciências e pesquisa. Campinas-SP: Papirus, 2008.

ÁVILA, Maria Betânia. O tempo do trabalho doméstico remunerado Entre cidadania e servidão. In.: ABREU, Alice Rangeu de Paiva; HIRATA, Helena; LOMBARDI, Maria Rosa (Orgs). Gênero e trabalho no Brasil e na França: perspectivas interseccionais. São Paulo: Editora Boitempo, 2016.

BIROLI, Flávia. Gênero e desigualdades: os limites da democracia no Brasil. São Paulo: Boitempo, 2018.

BRUSCHINI, Cristina; LOMBARDI, Maria Rosa. A bipolaridade do trabalho feminino no Brasil contemporâneo.Cadernos de Pesquisa, n.110, p.67-104, julho, 2000.

Trabalho feminino: Trajetória de um Tema, Perspectivas para o Futuro. In.: Seminário Desafios do Feminismo, Museu Histórico Nacional Centro Interdisciplinar de Estudos Contemporâneos, UERJ. Rio de Janeiro, 20/21 maio, 1993.

FALQUET, Jules. Repensar as relações sociais de sexo, classe e "raça" na globalização neoliberal. Tradução de Renata Gonçalves. In.: Sexe, classe, race. Pour une épistémologie de la domination. Paris: PUF, 2008.

GUIMARÃES, Nadya Araujo; BRITO, Murillo Marschner Alves de. Mercantilização do feminino - A visibilidade do trabalho das mulheres no Brasil. In.: ABREU, Alice Rangeu de Paiva; HIRATA, Helena; LOMBARDI, Maria Rosa (Orgs). Gênero e trabalho no Brasil e na França: perspectivas interseccionais. São Paulo: Editora Boitempo, 2016.

HIRATA, Helena. Globalização e divisão sexual do trabalho. Cadernos Pagu, n. 17-18, p. 139-156, Campinas, 2002.

; KERGOAT, Danièle. Novas configurações da divisão sexual do trabalho. Tradução Fátima Murad. In.: Cadernos de Pesquisa, v. 37, n. 132, p. 595-6o9, set./dez., 2007. 
IPEA. Retrato das Desigualdades de Gênero e Raça: 1995 a 2005. Brasília: IPEA, 2017. Disponível em: http://www.ipea.gov.br/retrato/. Acesso em 29 de outubro de 2018.

LAVINAS, Lena; CORDILHA, Ana Carolina; CRUZ, Gabriela Freitas da. Assimetrias de gênero no mercado de trabalho no Brasil - Rumos da formalização. In.: ABREU, Alice Rangeu de Paiva; HIRATA, Helena; LOMBARDI, Maria Rosa (Orgs). Gênero e trabalho no Brasil e na França: perspectivas interseccionais. São Paulo: Editora Boitempo, 2016.

MARUANI, Margaret; MERON, Monique. Como contar o trabalho das mulheres? - França, 1901-2011. In.: ABREU, Alice Rangeu de Paiva; HIRATA, Helena; LOMBARDI, Maria Rosa (Orgs). Gênero e trabalho no Brasil e na França: perspectivas interseccionais. São Paulo: Editora Boitempo, 2016.

SAFFIOTI, Heleieth. A mulher na sociedade de classes: mito e realidade. Petrópolis-RJ: Vozes, 1976.

Gênero, patriarcado, violência. São Paulo: Editora Fundação Perseu Abramo, 2004.

SCOTT, Joan. Gênero: uma categoria útil de análise histórica. Educação e Realidade, Porto Alegre-RS, v. 1, n. 2, jul./dez., 1995.

SOUZA-LOBO, Elisabeth. A classe operária tem dois sexos: trabalho dominação e resistência. 2. ed. São Paulo: Editora Fundação Perseu Abramo, 2011.

STAKE, Robert E. Pesquisa qualitativa: estudando como as coisas funcionam. Porto Alegre: Penso, 2011. 